\title{
Distance relay performance in future converter dominated power systems
}

\author{
Sarkar, Moumita; Jia, Jundi; Yang, Guangya
}

Published in:

Proceedings of 12th IEEE PES PowerTech Conference

Link to article, DOI:

10.1109/PTC.2017.7981144

Publication date:

2017

Document Version

Peer reviewed version

Link back to DTU Orbit

Citation (APA):

Sarkar, M., Jia, J., \& Yang, G. (2017). Distance relay performance in future converter dominated power systems. In Proceedings of 12th IEEE PES PowerTech Conference IEEE. https://doi.org/10.1109/PTC.2017.7981144

\section{General rights}

Copyright and moral rights for the publications made accessible in the public portal are retained by the authors and/or other copyright owners and it is a condition of accessing publications that users recognise and abide by the legal requirements associated with these rights.

- Users may download and print one copy of any publication from the public portal for the purpose of private study or research.

- You may not further distribute the material or use it for any profit-making activity or commercial gain

- You may freely distribute the URL identifying the publication in the public portal

If you believe that this document breaches copyright please contact us providing details, and we will remove access to the work immediately and investigate your claim. 


\section{Distance Relay Performance in Future Converter Dominated Power Systems}

\author{
Moumita Sarkar \\ Wind Energy Department \\ Technical University of Denmark \\ Roskilde, Denmark \\ mosar@dtu.dk
}

\author{
Jundi Jia, Guangya Yang \\ Center of Electric Power and Energy \\ Technical University of Denmark \\ Kgs. Lyngby, Denmark
}

\begin{abstract}
Increasing penetration of converter-based generations in power system has led to new system challenges. Short circuit power response from converter-based generations is different from that of traditional synchronous generators. Power electronic converters can be designed for over-current only up to 1.1-1.25 times of its nominal value. Low availability of short circuit power can cause many challenges such as misoperation of distance relays. The aim of this paper is to investigate the effect of converter dominated systems on performance of distance relays. Backup functionality of the distance relay is major concern as miscoordination of backup relays in case of cascading faults can lead to severe stress in system, which can develop into blackout. In this paper, response of relays in traditional system is compared with response of relays in low short-circuit-current power systems. Impact of converter controls on fault current response of converter-based generations is also investigated.

Index Terms - Converter control, distance relays, power system protection, system modelling
\end{abstract}

\section{INTRODUCTION}

Increasing environmental concerns have led to decrease in fossil fuel generated power in majority of electrical power systems and in turn paved way for increase in power generation by Renewable Energy Sources (RES). According to European Network Transmission System Operators for Electricity (ENTSO-E) report, RES will play preeminent role with a forecasted increase in installed capacity of wind and solar by $80 \%$ and $60 \%$ respectively by 2025 [1]. Such huge penetration of RES will lead to replacement of synchronous generators with RES which are mostly interfaced to the grid through power electronic converters. To ensure safety of power electronic components, converters are designed to generate maximum current which is 1.1-1.25 times its rated current [2], [3]. This implies that during fault, converter-based RES can generate short circuit current, which is less than that compared to synchronous generators. Therefore, Short Circuit Power (SCP) will reduce in the system. One major impact of decreasing SCP will be on the behaviour of protective relays. One protective relay scheme - distance relaying measures voltage and current to determine electrical distance from fault location. Thus, both voltage and current during fault plays significant role in proper operation of distance relay. A distance relay connected to a low SCP system may not have enough current for its accurate operation. This is a threat posed due to increase in RES penetration.
On the other hand, presence of power electronic converter interface in modern day RES offers flexibility in control of short circuit current. Since short circuit current mainly depends on control action of converter, converter parameters can be tuned as per desired short circuit response considering converter capabilities. This gives a major advantage for RES. Converter controls can be tuned for fast or slow reactive current response, delayed response, balanced response in case of unbalanced faults etc. Nevertheless SCP remains low in system dominated by converter-based generations.

Multiple contingency events can cause transients, which can be miscalculated by protective relays as backup zone faults and cause erroneous tripping of transmission lines and equipments. Therefore it is of particular interest to study cascading or multiple faults on protective relay performance in low SCP system with converter-based generations. Specially if multiple outages cause disconnection of synchronous generator or a part of system with synchronous generators. Such event will cause SCP to reduce further as power support from synchronous generator will reduce. Hence relay performance will depend on SCP from RES only. This in turn implies that relay performance will be dependent on converter controls of RES. This provides motivation for this study where performance of zone 2 distance relay is studied for different converter control parameters in case of multiple faults in low SCP systems.

Effect of converter controlled generation on transmission line protection have been studied in [4], [5], [6]. Li et. al. [4] studied zone 1 protection performance of distance relay with varying degrees of RES. Roy et. al. [5] studied the impact of full converter based Type IV Wind Turbine Generator (WTG) on various protection schemes for both balanced and unbalanced faults. With the control strategy used in [5], it is observed that low fault current and absence of negative and zero sequence current during unbalanced faults affect performance of protective relays. Investigation of transmission line protection employing different protection schemes in a system with converter controlled generation is done by Holder et. al. [6]. Hooshyar et. al. [7] has shown that the impedance seen by a relay on a line connected to WTG does not represent true fault location during first few cycles of a balanced fault. This can result in zone 1 tripping of relays for faults occurring in zone 2. 
$\mathrm{He}$ and Liu [8] describe the effect of Voltage Source Converter (VSC) based HVDC control on zone 2 setting of backup relays. For a certain system topology, the relay under study may over estimate zone 2 fault as zone 3 fault [8]. He et. al. [9] shows that when a fault occurs near Point of Common Coupling (PCC), backup protection can overestimate zone 2 fault. This can lead to miscoordination of relay tripping, causing the fault to persist beyond its critical clearing time, thereby leading to cascading events. Impact of cascading or multiple faults on protective relay performance in low SCP systems with converter-based generations still remains unevaluated. This paper studies impact of cascading or multiple faults on distance relay performance with converterbased generations.

Short circuit current contribution of converter-based generation depends on reactive current output controlled by the VSC. As total current output of converter is limited to 1.1-1.25 p.u., generations with converter interfaces have a low short circuit current contribution. Li et. al. [4] studied the impact of various converter parameters like current ramp rate, response delay, output fault current level on zone 1 distance protection. He and Liu [8] shows that impact of HVDC control on protective relay schemes can prevent system instability.

ENTSO-E specifies grid codes to ensure safe and reliable operation of power system, particularly during faults - one such being the reactive current rise time requirement. Different Transmission System Operators (TSO) across Europe have different reactive current rise time requirements. Curzi et. al. in [10] summarises fault ride through reactive current rise time requirements of various European grid codes. Rise time varies from $30 \mathrm{~ms}$ to $150 \mathrm{~ms}$, while ENTSO-E recommends rise time of $10 \mathrm{~ms}$. The impact of varying reactive current rise time of performance of distance relay is also studied in this paper.

Organisation of the paper is as follows: Section II describes the system model used. WTG model used with Grid Side Voltage Source Converter (GSVSC) control technique and grid synchronisation method used here is described. In Section III, results of different case studies are compared and analysed. Section IV concludes the paper.

\section{Type IV Wind Turbine Generator Model}

Real Time Digital Simulator (RTDS) has been used in this work to simulate real time Electromagnetic Transient (EMT) simulations. For study of power system protection system, the stator flux transients play an important role as these cause transients in the short circuit currents. Thus EMT simulation is required for protection studies [11].

\section{A. System Configuration}

A variable speed, Permanent Magnet Synchronous Generator (PMSG) based, Type IV WTG with full-scale converter as described in [12] and [13] is used for studies in this paper. Fig. 1 represents the schematic diagram of a PMSG based Type IV WTG. The stator of the machine is connected to the grid through back-to-back VSCs. In this model, a 2 MVA, $4 \mathrm{kV}$ PMSG is connected to a $2 \mathrm{MW}$ Wind Turbine (WT).

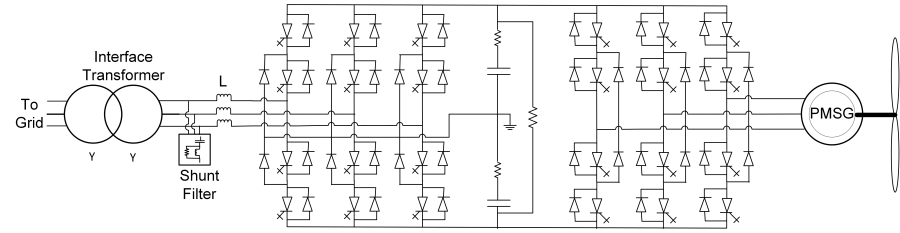

Fig. 1: Schematic diagram of permanent magnet synchronous generator based wind turbine generator with back-to-back voltage source converters

To transfer power from PMSG to grid, back to back 3 level Neutral Point Clamped (NPC) VSCs are used. Both VSCs are controlled using space vector control strategy as described in [14], [15]. A shunt connected high pass filter is used to filter the harmonics [13]. The chopper in DC link is used to dissipate the surplus power that cannot be supplied to the grid.

The PMSG is modelled in synchronously rotating dq reference frame. Stator flux is aligned along $\mathrm{d}$-axis and $\mathrm{q}$-axis leads it by 90 degrees. Main function of Machine Side VSC (MSVSC) is to optimize rotor speed to harvest maximum energy from wind [13]. To attain this objective, MSVSC controls stator current. The q-axis component of stator current maintains the power requirement of WT. The d-axis component of stator current controls armature reaction flux to maintain the reactive power at minimum (when output of machine is $<=1$ p.u.) [16]. It is assumed in the simulations that wind speed remains constant during the time of simulation. Due to complete decoupling of stator from the grid, short circuit current contribution from WTG depends on control strategy of GSVSC which is described in the following sub-section.

\section{B. Grid Side Voltage Source Converter Control}

GSVSC control is shown in Fig. 2. The function of GSVSC

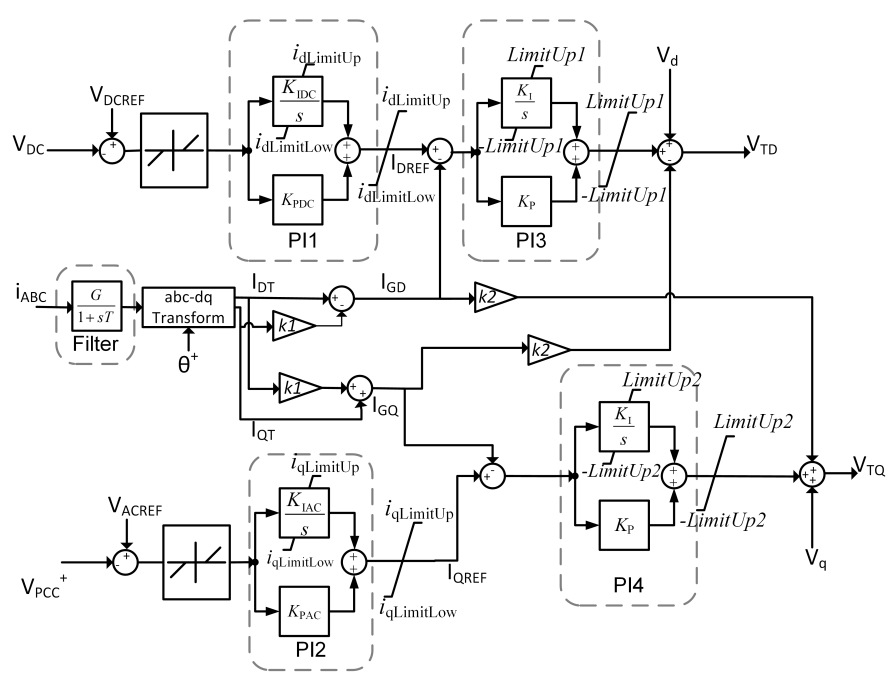

Fig. 2: Grid side voltage source converter control

is to maintain DC-link and PCC voltage by controlling active and reactive power flows respectively. Similar to MSVSC, space vector control strategy is employed in GSVSC. This 
enables independent control of active and reactive power flow between grid and GSVSC. Description of parameters are given in Table I. As shown in Fig. 2, grid current is

TABLE I: Parameters of GSVSC Control Scheme

\begin{tabular}{cc}
\hline Symbol & Description \\
\hline$V_{D C}$ & Measured DC link voltage \\
$V_{D C R E F}$ & DC voltage reference \\
$V_{P C C+}$ & Measured positive sequence PCC voltage \\
$V_{A C R E F}$ & PCC voltage reference \\
$i_{a b c}$ & Measured 3 phase grid current \\
$\theta^{+}$ & Calculated positive sequence phase angle \\
$I_{G D}, I_{G Q}$ & Calculated d-axis and q-axis grid current \\
$k 1$ & phase shift compensation factor \\
$k 2$ & cross coupling coefficient $(\omega L)$ \\
$K_{I D C}, K_{P D C}, K_{I A C}$, & PI controller parameters \\
$K_{P A C}, K_{I}, K_{P}$ & Calculated upper \& lower limit of $I_{d}$ \\
$I_{d L i m i t U p}, I_{d L i m i t L o w}$ & Calculated upper \& lower limit of $I_{q}$ \\
$I_{q L i m i t U p}, I_{q L i m i t L o w}$ & Calculated $I_{d} \& I_{q}$ reference \\
$I_{D R E F}, I_{Q R E F}$ & d-axis \& q-axis voltage \\
$V_{d}, V_{q}$ &
\end{tabular}

filtered and decomposed into d-axis and q-axis components. The d-axis current is used to control DC-link voltage and the q-axis current is used to control reactive power, hence the PCC voltage [16]. The PI controller, PI1 is used to generate reference $I_{d}$ current. This is then compared with measured grid $I_{d}$ and the error is passed to PI3. Similarly PI2 is used to generate reference $I_{q}$ current, which is then compared with measured grid $I_{q}$ and the error is passed to PI4. D-axis and $\mathrm{q}$-axis voltage values are generated as described by Pena et. al. in [16]. Limit of PI controller, PI1, is set according to 1.

$$
I_{d}=\sqrt{I_{\max }{ }^{2}-I_{q}{ }^{2}}
$$

where,

- $I_{d}=\mathrm{d}$-axis current

- $I_{q}=\mathrm{q}$-axis current

- $I_{\max }=$ maximum current output of converter

Limits for output of PI controller, PI2, are set according to reactive power requirements of the Danish grid code [17] as illustrated in Fig. 3. Fig. 3 shows that if PCC voltage is

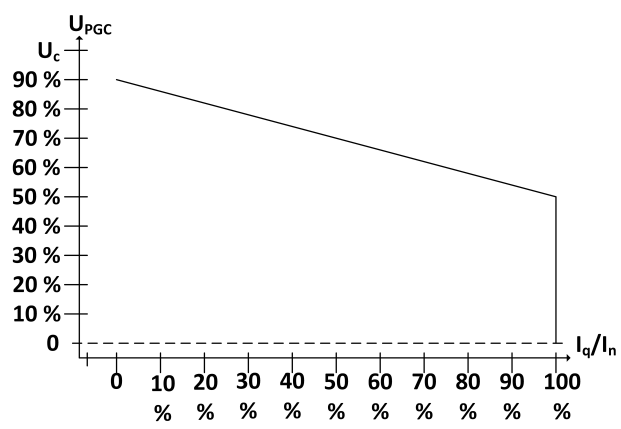

Fig. 3: Reactive current requirement during voltage dip

above 0.9 p.u., the Wind Power Plant (WPP) is not required to generate any reactive current. When PCC voltage falls below 0.9 p.u., reactive current is generated according to the droop characteristic specified in Fig. 3. Below 0.5 p.u., WPP is required to generate reactive current which is equal to $100 \%$ of its nominal current.

\section{Grid Synchronisation}

For desired operation of WTG during system faults, GSVSC control needs information about grid voltage for proper synchronisation with the grid. Performance of normal PLL under unbalanced conditions and in presence of harmonics is not satisfactory [18]. In power system, Synchronous Reference Frame - PLL (SRF-PLL) is most commonly used for grid synchronisation [18]. SRF-PLL transforms the grid voltage into dq-reference frame. This gives dc value of the voltage, which makes it easy to control [18]. SRF-PLL is a frequency adaptive PLL designed to perform well under balanced conditions without harmonics. When there is voltage unbalance and distortions in the system, performance of SRF-PLL can be improved by using Dual Second Order Generalized Integrator - PLL (DSOGI-PLL). Fig. 4 shows the block diagram for DSOGI-PLL. DSOGI-PLL uses frequency adaptive positive

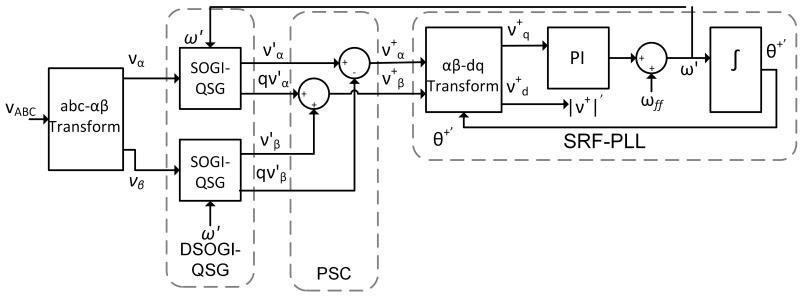

Fig. 4: Block diagram of Dual Second Order Generalized Integrator - PLL

sequence detection technique [19]. The positive sequence qaxis voltage is then applied to the SRF-PLL.

\section{System STUdies}

To study the performance of distance relays in low SCP systems, the Type IV WTG with the GSVSC control methodology and grid synchronisation technique as explained in Section II is connected to the benchmark 9-bus system. The benchmark 9-bus system consists of 9 buses, 3 generators, 6 transmission lines and 3 transformers [20]. To simulate future power system with low SCR, low SCP, one of the synchronous generators is replaced by WTG. Fig. 5 shows the single line diagram of the modified 9-bus system. Four new buses - 10, 11, 12 and $13-$ are added in the modified 9-bus system. It can be seen from Fig. 5, two parallel lines each $10 \mathrm{~km}$ long are added between PCC and the grid such that the Short Circuit Ratio (SCR) reduces to 2.165. As defined by "IEEE Guide for Planning DC Links Terminating at AC Locations Having Low Short-Circuit Capacities" [21], for ac/dc systems, if SCR lies between 2 and 3 the system can be classified as weak system. To simulate low SCP system, transmission lines are added between the two synchronous generators and the grid. Some capacitor banks are also added to maintain bus voltages at nominal values. 


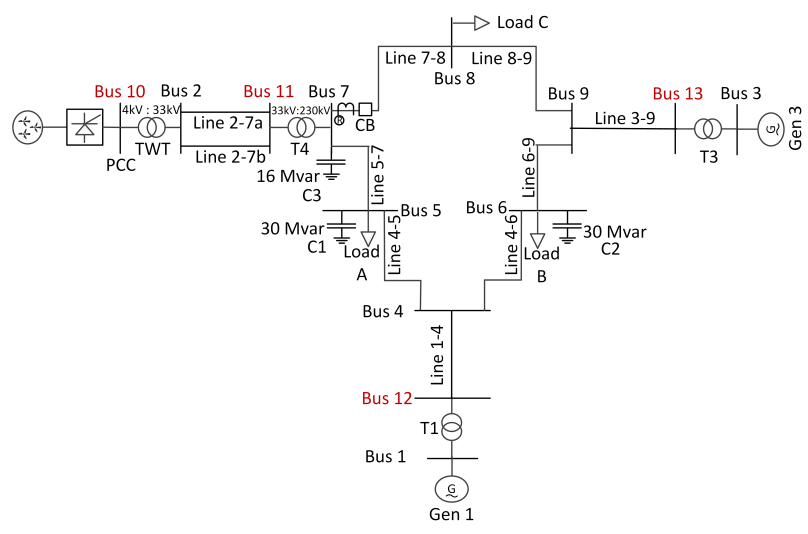

Fig. 5: Modified 9-bus low short circuit power system

\section{A. Fault Description and Relay Settings}

Performance of distance relay for backup protection (zone 2 setting) is studied in this paper. For this purpose, a relay at the bus 7 end of the Line 7-8 is considered. A three phase bolted fault is simulated on Line 8-9, such that the fault is at a distance of $10 \%$ from bus 8 . It is assumed that the circuit breaker at bus 8 is stuck and cannot clear the fault. Therefore the relay at bus 7 acts as a backup protection. Zone 2 setting of the relay is set as $120 \%$ of length of Line $7-8$. Thus the relay sees the fault in its zone 2 reach as it is within $120 \%$ of the line length. The relay takes $20 \mathrm{~ms}$ to detect the fault. Being zone 2 backup relay, it has coordination time of $300 \mathrm{~ms}$. After $300 \mathrm{~ms}$, since the fault is still not cleared, the relay sends trip signal to the circuit breaker. The circuit breaker takes $50 \mathrm{~ms}$ to trip. Hence total fault clearing time is measured as $370 \mathrm{~ms}$.

\section{B. Case Studies}

Performance of distance relay in 9-bus benchmark system is taken as base case. Impact of low SCP system on performance of distance relay is analysed in terms of current and voltage seen by relay, measured impedance and fault impedance locus. Two scenarios are studied in this paper : (i) when there is single three phase balanced fault at Line 8-9 and (ii) when there are multiple outages in the system (it is assumed that Gen 1 is disconnected from the system due to fault in Line $1-4$, then the three phase fault at Line 8-9 occurs). Impact of different reactive current rise time (varying from $20 \mathrm{~ms}$ to $100 \mathrm{~ms}$ ) is also studied when there is a single fault in the system. Data obtained from RTDS are plotted in MATLAB for comparison and analysis.

\section{Base Case : 9-bus benchmark system}

The 9-bus benchmark system with 3 synchronous generators is a high SCP system. When a fault occurs in the system, all 3 generators provide SCP and voltage support. Fig. 6 shows the performance of distance relay in the 9-bus benchmark system. Fig. 6a , Fig. 6b and Fig. 6c shows current, voltage and measured impedance respectively, as seen by the relay when a 3 phase fault occurs in Line 8-9. Fig. 6d shows fault impedance locus. Measurements are taken on the secondary

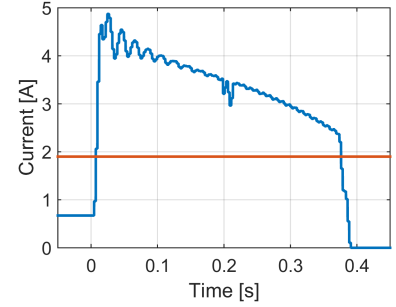

(a) Current

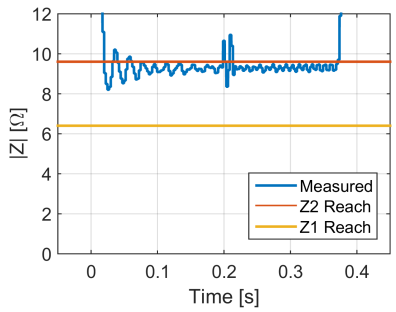

(c) Measured impedance

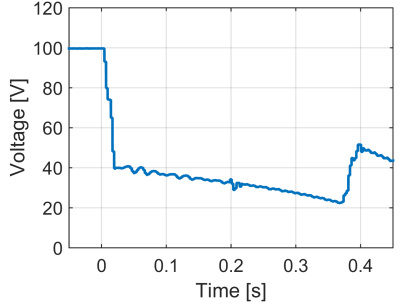

(b) Voltage

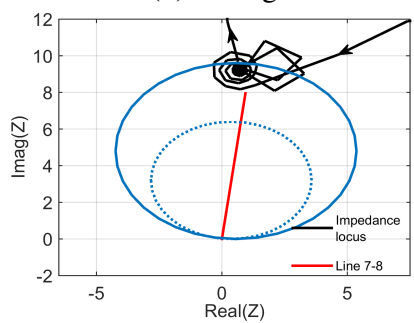

(d) Fault impedance locus
Fig. 6: Distance relay performance for 9-bus benchmark system

side of instrument transformers as seen by the relay. It can be observed that the fault impedance locus enters zone 2 setting of the relay and oscillates about a point close to zone 2 boundary for $300 \mathrm{~ms}$. Since the fault is still not cleared after $300 \mathrm{~ms}$, the relay at bus 7 acts as backup protection and trips; thereby clearing the fault. The fault impedance in Fig. $6 \mathrm{~d}$ lies entirely in zone 2. As per the system configuration, there are two infeeds of fault current. The drooping nature of current as seen in Fig. 6a is due to the phase difference between two current infeeds. Since the phase angle between two infeeds vary during the fault, the resulting current through the relay decreases.

\section{Case : Single fault in modified 9-bus system}

Fig. 7 shows distance relay performance for a fault in modified 9-bus system. Current and voltage (RMS value) as seen by the relay are shown in Fig. 7a and Fig. 7b. The magnitude of the measured impedance is shown in Fig. 7c. The fault impedance locus is shown in Fig. 7d. From Fig. 7a, it can be observed that the current seen by the relay during fault is greater than the pickup current setting of the relay. The initial dip in impedance as seen in Fig. 7c is due to sag in PCC voltage. But as PCC voltage recovers, the impedance measured by the relay increases, remaining within its zone 2 reach. It can be observed from Fig. 7d, fault locus moves close to zone 1 setting during first few cycles of fault initiation. Then it moves towards the zone 2 boundary and remains along the boundary until the relay trips after $300 \mathrm{~ms}$. This characteristic of the relay is because of the low SCP system where voltage drop during fault is quite severe. It is to be noted from Fig. 7a, current in the relay remains constant during the fault. As the PLL in GSVSC is modelled as fast responding PLL which track changes in grid side voltage accurately, during fault the phase difference between two current infeeds to the relay 


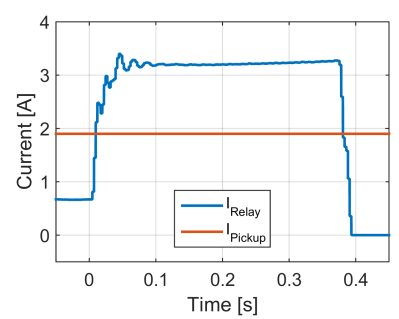

(a) Current

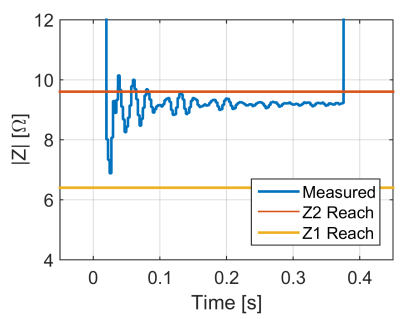

(c) Measured impedance

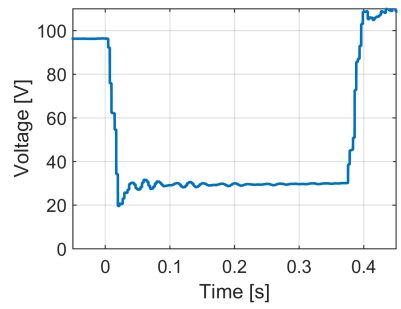

(b) Voltage

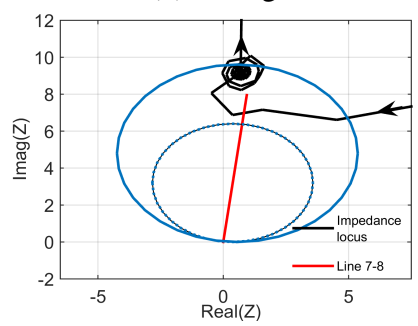

(d) Fault impedance locus
Fig. 7: Distance relay performance for single fault in modified 9-bus system

remains constant. Grid synchronisation in low SCP systems is important as short circuit current in such system is less. If current through relay decreases due to phase angle difference of infeed currents, relay can fail to operate due to insufficient pickup current, particularly for zone 2 setting.

\section{E. Case : Multiple faults in modified 9-bus system}

Fig. 8 shows distance relay performance when there are multiple outages in modified 9-bus system. Fig. 8a, Fig. 8b

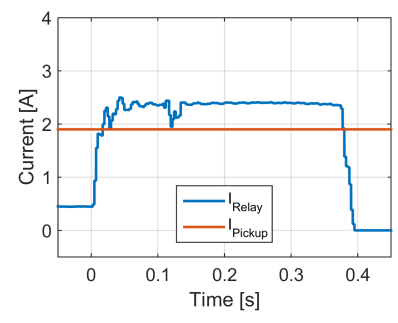

(a) Current

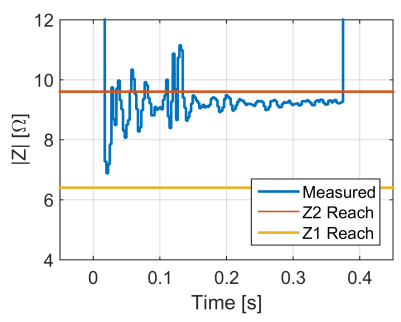

(c) Measured impedance

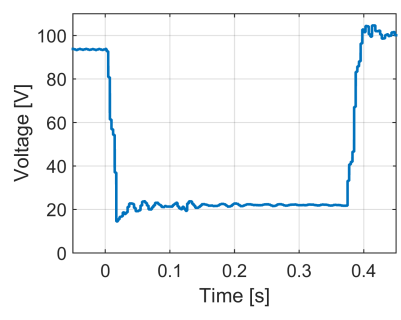

(b) Voltage

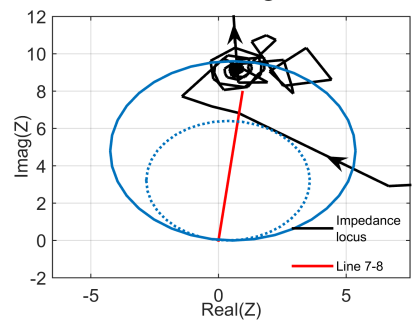

(d) Fault impedance locus
Fig. 8: Distance relay performance for multiple faults in modified 9-bus system

and Fig. 8c shows current, voltage and measured impedance, respectively, as seen by relay. The fault impedance locus is shown in Fig. 8d. When compared with the single fault in modified 9-bus system, it can be observed that, current and voltage seen by the relay in this case have reduced. Percentage decrease in voltage is greater than percentage decrease in current. Since the current is still greater than pickup current, the relay trips. The measured impedance remains almost constant. However, during first few cycles, dip in measured impedance is larger in this case due larger voltage dip at PCC. This causes the fault impedance locus to move closer towards zone 1 reach of the relay as observed in Fig. 8d. This behaviour may lead to false tripping of relay.

\section{F. Case : Effect of varying reactive current rise time for single fault in modified 9-bus system}

Fig. 9a and Fig. 9b show reactive current and reactive power response of WTG for reactive current rise time varying

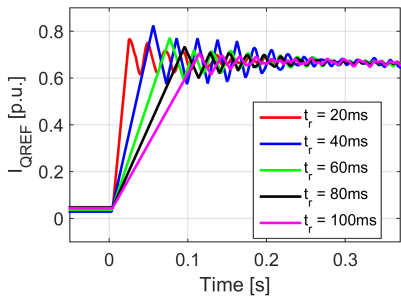

(a) Reactive current

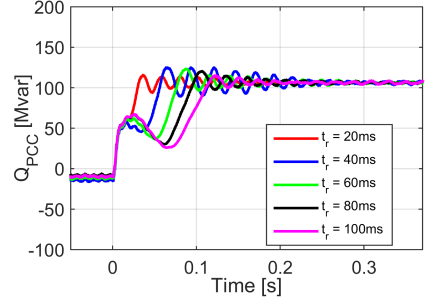

(b) Reactive power
Fig. 9: Reactive current and reactive power output from wind turbine generator for varying rise time

from $20 \mathrm{~ms}$ to $100 \mathrm{~ms}$. Fig. 10 shows of PCC voltages for different rise times. Low rise time depicts, lower voltage dip

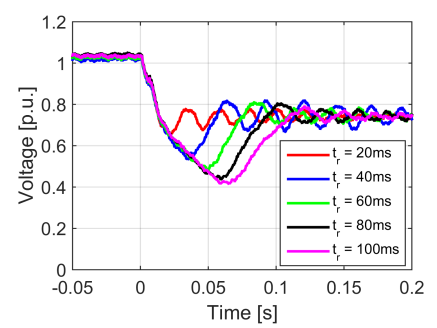

Fig. 10: PCC voltage dip and voltage recovery time with increase in rise time

at PCC as well as faster voltage recovery. When rise time is high, reactive power support from WTG is slow; resulting in increased voltage dip at PCC. Also it takes longer time for the PCC voltage to recover. However the steady state value remains same in all cases.

Fig. 11a, Fig. 11b, Fig. 11c show RMS current through relay, relay secondary side voltage and measured impedance respectively for different rise times. It can be observed that the initial response varies according to varying rise time and affect performance of distance relay. Low rise time causes voltage at PCC to dip lower at the beginning of fault. This can cause relay to estimate zone 2 fault as zone 1 fault and 


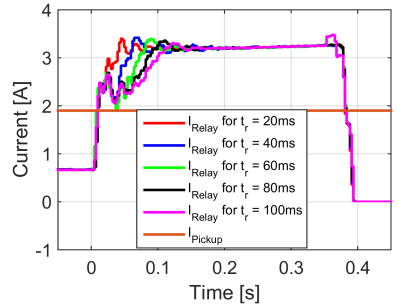

(a) Current

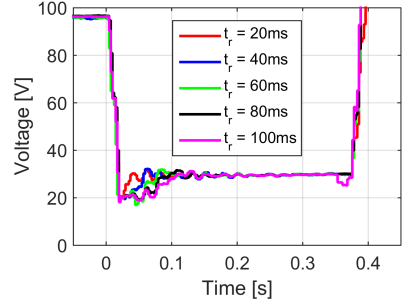

(b) Voltage

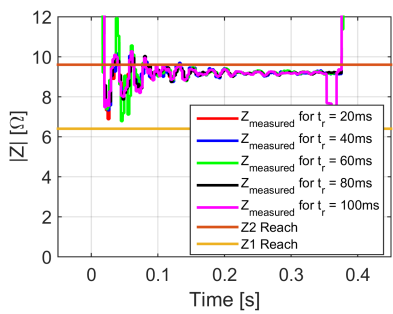

(c) Measured impedance

Fig. 11: Distance relay performance for different reactive current rise time

lead to false tripping specially if the system is stressed as in case of multiple faults. Therefore, faster reactive current rise time is desired in future converter dominated systems.

\section{CONCLUSION}

Distance relay performance is affected in low SCP system with high penetration of converter-based generations particularly during stressed conditions when there are multiple outages in the system. Due to increased voltage dip during faults in low SCP systems, initial fault impedance estimated by distance relay moves closer to zone 1 setting of relay even for zone 2 faults particularly during multiple system outages, when there is a lack of fast-contributed SCP. Short circuit current contribution of converter-based generations depends mainly on GSVSC. Hence GSVSC performance parameters like reactive current rise time, affects the short circuit response of converter-based generations. Fast reactive current rise time is essentially required for reliable performance of distance relays in low SCP system. GSVSC controller parameters should be tuned for fast reactive current response. If the system is already stressed due to unavailability of enough SCP, slow reactive current rise time following a fault can cause relay to trip falsely in zone 1 for zone 2 faults.

\section{REFERENCES}

[1] ENTSO-E, "Scenario outlook \& adequacy forecast," 2015. [Online]. Available: https://www.entsoe.eu/Documents/SDC\%20documents/ SOAF/150630_SOAF_2015_publication_wcover.pdf

[2] E. Muljadi, N. Samaan, V. Gevorgian, J. Li, and S. Pasupulati, "Short circuit current contribution for different wind turbine generator types," in IEEE PES General Meeting. IEEE, 2010, pp. 1-8.

[3] J. Keller and B. D. Kroposki, "Understanding fault characteristics of inverter-based distributed energy resources," National Renewable Energy Laboratory, Tech. Rep., 2010.
[4] R. Li, C. Booth, A. Dyśko, A. Roscoe, H. Urdal, and J. Zhu, "Protection challenges in future converter dominated power systems: demonstration through simulation and hardware tests," in International Conference on Renewable Power Generation (RPG 2015). IET, 2015, pp. 1-6.

[5] A. Roy and B. K. Johnson, "Transmission side protection performance with Type-IV wind turbine system integration," in North American Power Symposium (NAPS), 2014. IEEE, 2014, pp. 1-6.

[6] S. M. Holder, L. Hang, and B. K. Johnson, "Investigation of transmission line protection performance in an electric grid with electronically coupled generation," in North American Power Symposium (NAPS), 2013. IEEE, 2013, pp. 1-6.

[7] A. Hooshyar, M. A. Azzouz, and E. F. El-Saadany, "Distance protection of lines connected to induction generator-based wind farms during balanced faults," IEEE Transactions on Sustainable Energy, vol. 5, no. 4, pp. 1193-1203, 2014.

[8] L. He and C.-C. Liu, "Effects of HVDC connection for offshore wind turbines on AC grid protection," in IEEE Power \& Energy Society General Meeting. IEEE, 2013, pp. 1-5.

[9] L. He, C.-C. Liu, A. Pitto, and D. Cirio, "Distance protection of AC grid with HVDC-connected offshore wind generators," IEEE Transactions on Power Delivery, vol. 29, no. 2, pp. 493-501, 2014.

[10] M. Curzi, R. Sharma, and F. Martin, "In fault ride through reactive current rise time requirements of various european grid codes - analysis based on a full-converter wind turbine," Wind Energy, 2015.

[11] P. E. Sørensen, A. D. Hansen, P. Christensen, M. Mieritz, J. Bech, B. Bak-Jensen, and H. Nielsen, "Simulation and verification of transient events in large wind power installations," Tech. Rep., 2003.

[12] A. D. Hansen, Generators and power electronics for wind turbines. John Wiley and Sons, England, 2005.

[13] N. P. Strachan and D. Jovcic, "Stability of a variable-speed permanent magnet wind generator with weak ac grids," IEEE Transactions on Power Delivery, vol. 25, no. 4, pp. 2779-2788, 2010.

[14] B. Bose, Modern power electronics and AC drives. Prentice Hall, 2002.

[15] D. W. Novotny and T. A. Lipo, Vector control and dynamics of AC drives. Oxford university press, 1996.

[16] R. Pena, J. Clare, and G. Asher, "Doubly fed induction generator using back-to-back PWM converters and its application to variable-speed wind-energy generation," IEE Proceedings-Electric Power Applications, vol. 143, no. 3, pp. 231-241, 1996.

[17] Energinet.dk, "Technical regulation 3.2 .5 for wind power plants with a power output above $11 \mathrm{~kW})$, , 2015. [Online]. Available: http://energinet.dk/SiteCollectionDocuments/Engelske\% 20dokumenter/El/13-96336-43\%20Technical\%20regulation\%203.2. $5 \% 20$ for $\% 20$ wind $\% 20$ power\%20plants $\% 20$ with $\% 20$ a\%20power\% 20output\%20above\%2011\%20kW,\%20Rev.\%202.pdf

[18] F. Blaabjerg, R. Teodorescu, M. Liserre, and A. V. Timbus, "Overview of control and grid synchronization for distributed power generation systems," IEEE Transactions on industrial electronics, vol. 53, no. 5, pp. 1398-1409, 2006.

[19] P. Rodriguez, R. Teodorescu, I. Candela, A. V. Timbus, M. Liserre, and F. Blaabjerg, "New positive-sequence voltage detector for grid synchronization of power converters under faulty grid conditions," in Power Electronics Specialists Conference, 2006, pp. 1-7.

[20] P. M. Anderson and A. A. Fouad, Power system control and stability. John Wiley \& Sons, 2008.

[21] IEEE Guide for Planning DC Links Terminating at AC Locations Having Low Short-Circuit Capacities, IEEE Std. 1997. 